УДК 549.322

DOI $10.21661 / \mathrm{r}-554271$

\title{
Онуфриенок В.В.
}

\section{ФОРМИРОВАНИЕ МИНОРНЫХ ЭЛЕМЕНТОВ В МИНЕРАЛАХ}

Аннотация: методами микрозондоваго анализа (ЕРМА) исследовались минеральл пирит и халькопирит Енисейского кряжа (Красноярский край). Рассчитаны плотности точечных дефектов и атомов примеси. На основании расчетов представлень зависимости, доказывающих формирования атомов примеси (минорных элементов) в результате ядерный синтез в коре Земли.

Ключевые слова: минорные элементы, ядерный синтез и распад, халькопиpum, nupum.

Введение. Наша планета (Земля) имеет особенности в своем строении - тонкая кора покрывает раскаленную магму. Следует заметить, что кора составляет 1\% от массы Земли. Важно отметить два момента, первое - это потоки тепловой энергии, исходящие от центра Земли и второе - выброс магмы вулканами, кристаллизация которой и порождает появление различных минералов [1; 2].

Высокая температура внутри Земли создается за счет распада радиоактивных элементов - урана, радия. Уран и радий образуются при взрыве сверхновой. Стадии горения звезд происходят по схеме: горения водорода, гелия, углерода, неона, кислорода и горения кремния. Последний процесс является финальной стадией эволюции звезды за счёт термоядерных процессов. После её окончания в ядре звезды больше не остаётся доступных термоядерных источников энергии, поскольку в результате горения кремния образуются ядра группы железа, которые имеют максимальную энергию связи на один нуклон и более неспособны к термоядерным экзотермическим реакциям. Горение более тяжёлых элементов не происходит, поскольку при таких реакциях энергия уже не выделяется, а поглощается. Так становится понятно, почему у Земли железное ядро - Земля есть осколок отгоревшей звезды, сверхновой. 
Распад радия происходит по схеме: ${ }_{91} \mathrm{~Pa}-{ }_{92} \mathrm{U}+\mathrm{e}^{-}+\tilde{v}_{\mathrm{e}}$, насыщая ядро нейтронами. По существу, распадается нейтрон в ядре по схеме $n \rightarrow p+e^{-}+\tilde{v}$. Такие нейтроны могут возникать в результате радиоактивного распада. Насыщенное нейтронами ядро нестабильно и со временем распадается, освобождая нейтроны $[3 ; 4]$.

Отметим, что нейроны имеют нейтральный электрический заряд и при взаимодействии с ядром им не нужно преодолевать кулоновское отталкивание. Когда медленный нейтрон, потеряв часть своей энергии на своем пути через магму, подойдя близко к ядру какого-то элемента минерала коры Земли, может быть захвачен им. Захваченный нейтрон возбуждает ядро вследствие выделения энергии связи порядка 7 Мэв, которая может быть выделена в виде $\gamma$-кванта. Реакция приводит к образованию изотопа с увеличенным на единицу массовым числом: $\mathrm{Z}^{\mathrm{A}}+{ }_{0} \mathrm{n}^{1} \rightarrow \mathrm{Z}^{\mathrm{A}+1}+\mathrm{h} v$.

Например, ${ }_{27} \mathrm{Co}^{59}+{ }_{0} \mathrm{n}^{1} \rightarrow{ }_{27} \mathrm{Co}^{60} \rightarrow{ }_{28} \mathrm{Ni}^{60}+\beta^{-}+\mathrm{h} v$. По аналогичной схеме происходит не только синтез никеля, но и кобальта из железа.

Таким образом, все процессы, происходящие на Земле, каким-либо образом связаны с влиянием на них радиоактивности Земли.

Цель исследования: а) проанализировать атомы примеси в структуре халькопирита и пирита; б) на основе полученных результатов предложить модель формирования атомов примеси

Материал и методы исследования. Исследовался природный минеральный состав пирита и халькопирита из месторождений Енисейского кряжа (Красноярский край, Россия). Химический состав изучаемых образцов определялся рентгеноспектральным методом (XRS) на установке «Сamebax-Micro» в лаборатории микрозондового анализа СО РАН.

Результаты исследования и их обсуждение. Анализ халькопирита и пирита из месторождений Енисейского кряжа показывает, что присутствие в их структуре атомов Со и $\mathrm{Ni}$ (заметно меньше $\mathrm{Cu}$ и $\mathrm{Zn}$ ) намного превышает содержания примеси других элементов (таблица $1 ; 2)$. 
Результаты микрозондового анализа $(\tau)$ и расчетов плотности примесных атомов $(\omega)$ и вакантных позиций (n) в структуре халькопирита.

\begin{tabular}{|c|c|c|c|c|c|c|c|c|c|c|}
\hline $\begin{array}{c}2 \mathrm{~S} / \\
(\mathrm{Fe}+\mathrm{Cu} \\
)\end{array}$ & $\begin{array}{c}\mathrm{n} \\
10^{-2}\end{array}$ & $\begin{array}{c}\text { Сумма } \\
\text { при- } \\
\text { меси } \\
10^{-2}\end{array}$ & \multicolumn{2}{|c|}{$\mathrm{Ni}$} & \multicolumn{2}{|c|}{$\mathrm{Co}$} & \multicolumn{2}{c|}{$\mathrm{Zn}$} & \multicolumn{2}{c|}{ Au } \\
\hline$\beta /(\alpha+\varkappa)$ & $\begin{array}{c}\{\beta- \\
(\alpha+\varkappa)\} / 2\end{array}$ & $\Sigma \mathrm{X}_{\mathrm{i}}$ & $\omega \cdot 10^{-3}$ & $\begin{array}{c}\text { мac. } \\
\%\end{array}$ & $\omega \cdot 10^{-2}$ & $\begin{array}{c}\text { мac. } \\
\%\end{array}$ & $\omega \cdot 10^{-2}$ & $\begin{array}{c}\text { мac. } \\
\%\end{array}$ & $\omega \cdot 10^{-3}$ & $\begin{array}{c}\text { мac. } \\
\%\end{array}$ \\
\hline 1,007 & 0,655 & 0,2701 & - & - & 0,036 & 0,014 & 2,179 & 0,094 & 0,162 & 0,021 \\
\hline 0,994 & $-0,623$ & 0,2186 & - & - & 0,111 & 0,043 & 0,996 & 0,043 & 0,085 & 0,011 \\
\hline 1,012 & 1,156 & 0,1491 & - & - & 0,072 & 0,028 & 0,556 & 0,024 & 0,215 & 0,028 \\
\hline 1,008 & 0,831 & 0,5114 & - & - & 0,121 & 0,047 & 3,805 & 0,164 & 0,099 & 0,013 \\
\hline 0,991 & $-0,868$ & 0,1381 & - & - & 0,084 & 0,033 & 0,440 & 0,019 & 0,092 & 0,012 \\
\hline 0,994 & $-0,622$ & 0,1951 & - & - & 0,115 & 0,045 & 0,579 & 0,025 & 0,215 & 0,028 \\
\hline 1,001 & 0,055 & 0,2496 & 0,46 & 0,018 & 0,095 & 0,037 & 0,904 & 0,039 & 0,177 & 0,023 \\
\hline 0,993 & $-0,684$ & 0,1819 & - & - & 0,105 & 0,041 & 0,764 & 0,033 & - & - \\
\hline 1,013 & 1,246 & 0,1719 & - & - & 0,059 & 0,023 & 1,066 & 0,046 & 0,062 & 0,008 \\
\hline 1,015 & 1,447 & 0,1979 & 0,23 & 0,009 & 0,056 & 0,022 & 1,182 & 0,051 & - & - \\
\hline 0,998 & $-0,217$ & 0,1574 & - & - & 0,069 & 0,027 & 0,787 & 0,034 & 0,092 & 0,012 \\
\hline
\end{tabular}

Можно предположить, что атомы Со и $\mathrm{Ni}$ (а также $\mathrm{Cu}$ и $\mathrm{Zn}$ ) возникли в результате ядерного превращения ядра атома железа (Fe), так как находятся рядом в таблице Менделеева справа. Заметим, что слева элементов нет.

Рассмотрим структуру халькопирита $\mathrm{CuFeS}_{2}$, которая является сверхструктурой к типу сфалерита. В ней два катиона упорядоченно распределены в катионной подрешетке. Это упорядочение приводит к небольшому смещению анионов из позиций, отвечающих плотной упаковке. Элементарная ячейка сверхструктуры соответствует двум ячейкам типа сфалерита, поставленным друг на друга вдоль оси «с». Сфалерит $\mathrm{ZnS}$ является кубическим прототипом семейства структур, построенных по принципу структуры алмаза. Структура алмаза представляет собой трехмерный чрезвычайно жесткий каркас, в котором каждый атом окружен четырьмя соседями. Эти атомы образуют две взаимопроникающие 
подрешетки, каждая из которых занята атомами своего компонента в производной структуре сфалерита.

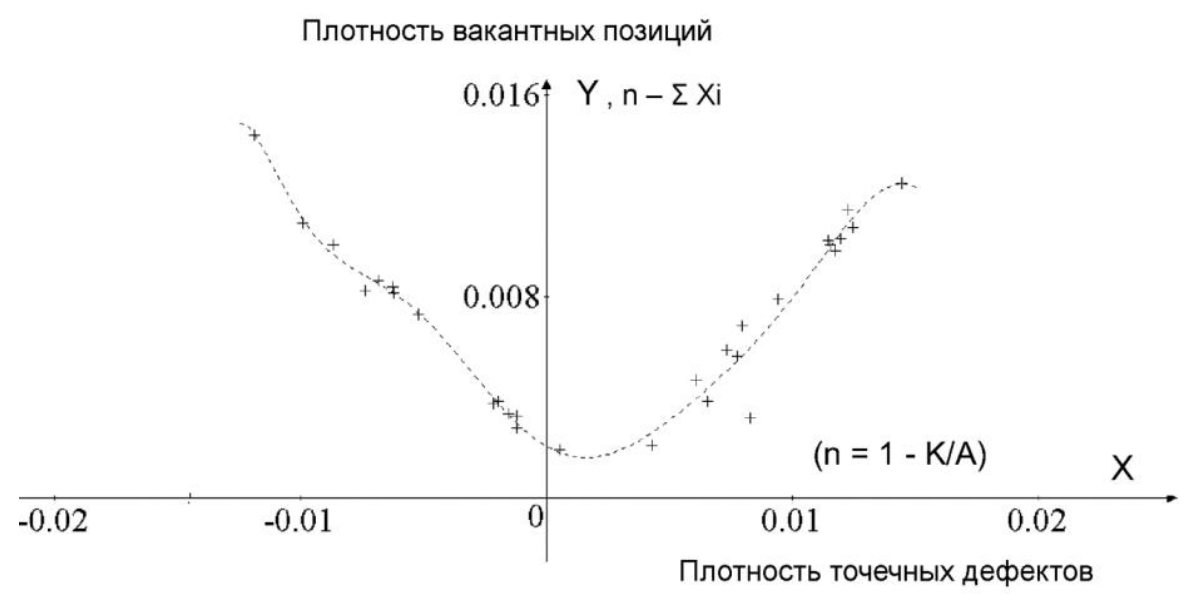

Рис.1. Зависимость плотности вакантных позиций в структуре халькопирита от плотности точечных дефектов в кристаллической матрице.

Таким образом, в элементарной ячейке - восемь атомов. Кристаллическая структура халькопирита аналогична структуре сфалерита, но в позициях цинка упорядоченно располагаются атомы меди и железа [5-7]. Из результатов анализа образцов следует, что халькопирит всегда является нестехиометрическим (табл. 1). Состав природного халькопирита лучше представлять формулой $\left(\mathrm{Fe}^{+3}\right)_{\alpha}\left(\mathrm{Cu}^{+1}\right)_{\varkappa}\left(\left(\mathrm{S}_{2}\right)^{-4}\right)_{\beta}$, поскольку в образцах варьируется соотношение $2 \mathrm{~S} /(\mathrm{Fe}+\mathrm{Cu})$. Если в кристаллической структуре минерала стехиометрического состава число катионов равно числу анионов, т.е. $1=\Sigma$ (катионов) $/ \Sigma($ анионов $)$, то число вакантных позиций, точечных дефектов, можно получить из отношения: $\mathrm{n}=1-\{\Sigma($ катионов $) / \Sigma($ анионов $)\}$. Также число вакантных позиций в структуре можно также рассчитать по формуле:

$\mathrm{n}=1-(1 / \mathrm{x})$, где $\mathrm{x}=2 \mathrm{~S} /(\mathrm{Fe}+\mathrm{Cu})$.

Отношение $2 \mathrm{~S} /(\mathrm{Fe}+\mathrm{Cu})$ можно определять по альтернативной формуле, a именно, как $\beta /(\alpha+x)$. 
Результаты химического анализа примеси в пирита

\begin{tabular}{|c|c|c|c|c|c|c|c|}
\hline $\begin{array}{c}\text { Плотность- } \\
\text { вакантных. } \\
\text { позиций }\end{array}$ & $\begin{array}{c}\text { Плотн.то } \\
\text { чечных } \\
\text { дектов }\end{array}$ & $\mathrm{Fe}^{+2}$ & $\left(\mathrm{~S}_{2}\right)^{-2}$ & $\begin{array}{c}\text { сумма ато- } \\
\text { мов примеси }\end{array}$ & $\mathrm{Cu}$ & $\mathrm{Co}$ & $\mathrm{Ni}$ \\
\hline $\begin{array}{c}\mathrm{n}-\Sigma \mathrm{X}_{\mathrm{i}}, \\
\cdot 10^{-2}\end{array}$ & $\mathrm{n}$ & $\chi$ & $\tau$ & $\Sigma \mathrm{X}_{\mathrm{i}} \cdot 10^{-2}$ & $\mathrm{X}_{\mathrm{Cu},} \cdot 10^{-3}$ & $\begin{array}{c}\mathrm{X}_{\mathrm{Co}}, \\
\cdot 10^{-2}\end{array}$ & $\begin{array}{c}\mathrm{X}_{\mathrm{Ni}}, \\
\cdot 10^{-2}\end{array}$ \\
\hline 1,89592 & $-0,02370$ & 1,0237 & 0,9881 & 0,4741 & 0,284 & 0,102 & 0,309 \\
\hline 0,03042 & $-0,00432$ & 1,0043 & 0,9978 & 0,4016 & 0,382 & 0,127 & 0,221 \\
\hline$-0,20501$ & $-0,00099$ & 1,0009 & 0,9995 & 0,3035 & - & 0,159 & 0,114 \\
\hline$-0,27701$ & $-0,00157$ & 1,0015 & 0,9992 & 0,4335 & 0,954 & 0,171 & 0,159 \\
\hline 0,32972 & $-0,00608$ & 1,0060 & 0,9969 & 0,2783 & 0,190 & 0,160 & 0,092 \\
\hline 1,50332 & 0,02142 & 0,9785 & 1,0107 & 0,6387 & 0,756 & 0,191 & 0,366 \\
\hline 0,01039 & $-0,01579$ & 1,0157 & 0,9921 & 0,5398 & 0,132 & 0,108 & 0,401 \\
\hline$-0,00016$ & 0,00173 & 0,9982 & 1,0008 & 0,1887 & 0,189 & 0,092 & 0,037 \\
\hline 0,00043 & $-0,00234$ & 1,0023 & 0,9988 & 0,1909 & 0,322 & 0,114 & 0,024 \\
\hline 0,00721 & 0,00954 & 0,9904 & 1,0047 & 0,2329 & 0,209 & 0,182 & - \\
\hline 0,00183 & $-0,00325$ & 1,0032 & 0,9983 & 0,1421 & - & 0,084 & 0,022 \\
\hline
\end{tabular}

Интерес представляет сопоставить плотность вакантных позиций и плотность всех точечных дефектов (рис.1). На рис.1 показана суммарная плотность вакантных позиций по абсолютной величине в структуре халькопирита. Анализ представленной на рис.1 графической зависимости позволяет сделать заключение, что при достаточно больших «n» эта суммарная плотность точечных дефектов увеличивается за счет атомов примеси в минерале. Кривая при больших значениях «n» стремится к насыщению. Насыщение - когда плотность точечных дефектов увеличивается только за счет атомов примеси. Это возможно только в том случае, если новые атомы возникают за счет синтеза атомов примеси в коре Земли. Схеме этого процесса предложена выше в виде анализа ядерных реакций. Для доказательства этого утверждения сравним полученные результаты с результатами анализа точечных дефектов в другом минерале - пирите. 


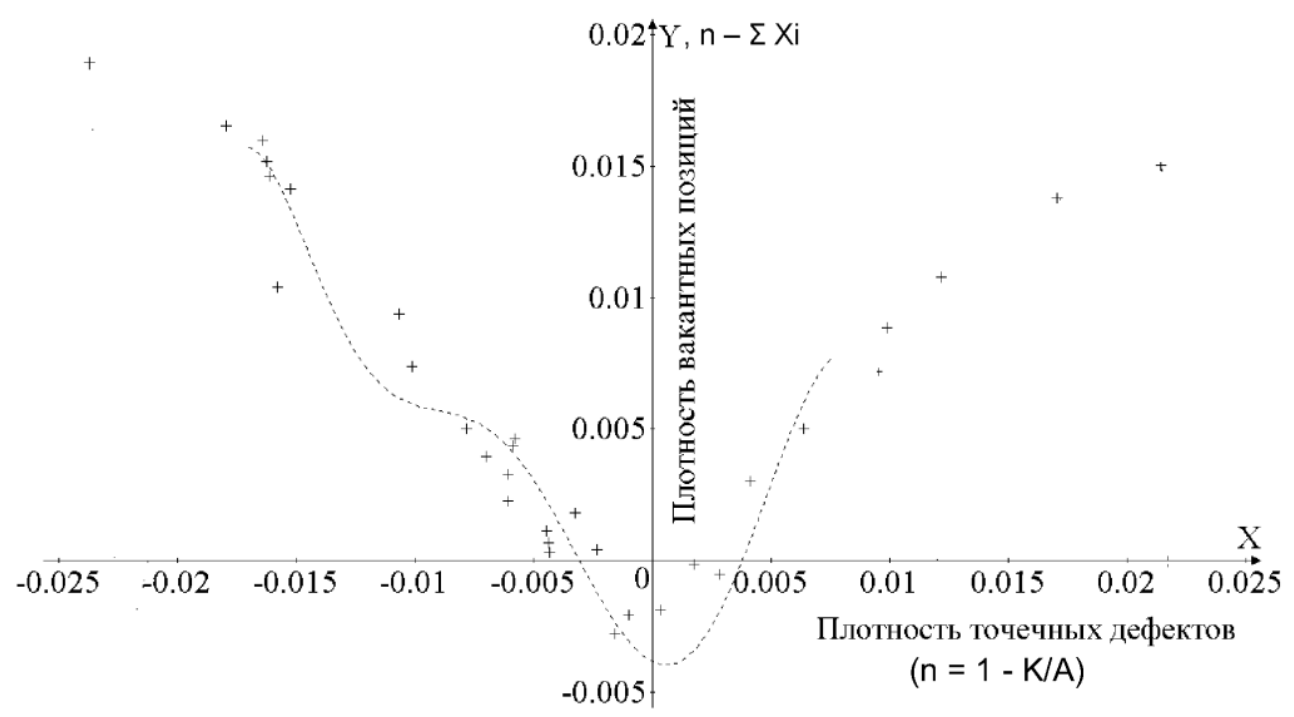

Рис.2. Зависимость плотности вакантных позиций от плотности точечных дефектов в кристаллической структуре пирита.

Для анализа различного рода атомов примеси в пирите необходимо рассмотреть кристаллическую структуру пирита. Пирит обычно представляется формулой $\mathrm{FeS}_{2}$, является парамагнетиком и обладает полупроводниковыми свойствами. Его состав также всегда является нестехиометрическим, поэтому состав природного пирит лучше представлять формулой $\left(\mathrm{Fe}^{+2}\right)_{\alpha}\left(\left(\mathrm{S}_{2}\right)^{-2}\right)_{\beta}$,

В структуре пирита атомы железа образуют ГЦК - подрешетку, а атомы S располагаются парами таким образом, что центры тяжести этих пар занимают середины ребер элементарной ячейки и ее центр. Оси «гантелей» $\mathrm{S}^{-2}$ располагаются под углом к направлению (100) вдоль четырех тройных непересекающихся осей структуры. Таким образом, в отличии от халькопирита, пирит обладает кубической структурой, в которой анионы сформированы в двухвалентные гантели, состоящие из двух атомов серы.

В случае изоморфного замещения пирит образовывает различные минералы. Например, если минерал содержит примесь кобальта, никеля, меди, то возможно, например, образование минералов вилламанинит ( $\mathrm{Cu}, \mathrm{Ni}, \mathrm{Co}, \mathrm{Fe}) \mathrm{S}_{2}$, бравоит(Fe,Ni) $\mathrm{S}_{2}$, и, при полном замещении атомов железа никелем и кобальтом, ваэсит $\mathrm{NiS}_{2}$ и катьерит $\mathrm{CoS}_{2}$. Результаты данного исследования, вероятно, можно применить и к этим минералам, а также, к их формированию. 
Изоструктурная группа пирита в общем случае представляется пространственной группой Ра3. В общем случае полного изоморфного замещения, минералы группы пирита можно представить в виде $\mathrm{AX}_{2}$, где А могут обозначать такие химические элементы, как $\mathrm{Au}, \mathrm{Co}, \mathrm{Cu}, \mathrm{Fe}, \mathrm{Mn}, \mathrm{Ni}, \mathrm{Os}, \mathrm{Pd}, \mathrm{Pt}, \mathrm{Ru}$. Под символом X в предложенной формуле могут быть $\mathrm{As}, \mathrm{Bi}, \mathrm{S}, \mathrm{Sb}, \mathrm{Se}$, Те. Атомы «A» занимают узлы гранецентрированной кубической решетки и окружены связанными в «гантель» «Х» атомами [8-11]. Поэтому выводы этой работы относятся и ко всей этой группе минералов.

Пирит отличается от халькопирита кристаллическим строением, тем не менее, рассмотренная выше зависимость аналогичная.

Заключение. Проведен сравнительный анализ точечных дефектов в структуре минералов - пирит и халькопирит. Найдены зависимости, которые можно объяснить только процессами ядерного синтеза в коре Земли. В результате ядерных реакций в ядре Земли и возникают протоны и нейтроны, которые в коре Земли захватываются атомами минерала. В результате возникают атомы примеси в структуре минерала, так как эти атомы переходят на другой номер в таблице Менделеева.

\section{Список литературы}

1. Arnett, W. D., Advanced evolution of massive stars. VII - Silicon burning / Astrophysical Journal Supplement Series, vol. 35, Oct. 1977, p. 145-159

2. Carlson R. W. Planetary science: A new recipe for Earth formation. 2015 doi:10.1038/520299a

3. Jordan T. H.. Structural Geology of the Earth's Interior // Proceedings of the National Academy of Sciences of the United States of America - 1979. - Vol. 76, - P. 4192-4200. - doi:10.1073/pnas.76.9.4192

4. Hall S.R. Crystal structures of the chalcopyrite series // The Canadian Mineralogist. -1975. - V. 13. - P.168-172.

5. Hix, W. Raphael; Thielemann, Friedrich-Karl Silicon Burning. I. Neutronization and the Physics of Quasi-Equilibrium. The Astrophysical Journal. 1996, V. 460: 869.. doi:10.1086/177016 
6. Larocque A.C.L., Hodgson C.J., Cabri L.J., Jackman J.A., Ion-microprobe analysis of pyrite, chalcopyrite and pyrrhotite from the Mobrun VMS deposit in northwestern Quebec: evidence for metamorphic remobilization of gold, The Canadian Mineralogist, V. 33, p. 373-388, 1995.

7. Makovicky E. Crystal structures of sulfides and other chalcogenides. // Sulfide Mineralogy and Geochemistry. 2006. V. 61. p. 7-125.

8. Онуфриенок В.В. Точечные дефекты и их влияние на физические свойства кристаллов» / В.В. Онуфриенок, А.В. Чжан. - Красноярск: Изд-во КГАУ, 2018. - $148 \mathrm{c}$.

9. Pearson WB The crystal chemistry and physics of metal and alloys. Wiley, New York, 1972, 826 p.

10. Rickard D, Luther G., Chemistry of Iron Sulfides, Chem. Rev., V. 107, p. 514-565, 2007. doi: 10.1021/cr0503658

11. Vaughan DJ, Craig JR Mineral chemistry of metal sulfides. Cambridge University Press, Cambridge, 1978, 493 p.

Виктор Васильевич Онуфриенок - канд. физ.-мат. наук, доцент, ФГБОУ ВО «Красноярский государственный аграрный университет», Красноярск, Россия. 